\title{
Conceptual Design of Battery Energy Storage for Aircraft Hybrid Propulsion System
}

\author{
Mohamed Rashed ${ }^{1}$, Jean-Marc Le Peuvedic ${ }^{2}$ and Serhiy Bozhko ${ }^{1}$ \\ ${ }^{I}$ Department of Electrical and Electronics Engineering, \\ University of Nottingham, Nottingham, UK \\ E-mail: mohamed.rashed@nottingham.ac.uk \\ ${ }^{2}$ Dassault Aviation \\ l'avionneur de Saint-Cloud, Saint-Cloud, France \\ Jean-Marc.Le-Peuvedic@ dassault-aviation.com
}

\begin{abstract}
The paper presents a conceptual design approach for Energy Storage (ES) devices in advanced hybrid propulsion system for small aircrafts. The study targets operational improvement and reduction of fuel consumption for different flight missions. Power sharing strategies for ES and the engine are proposed for cruise flight phase aiming to maximise the range and/or endurance for the available amount of fuel in the tank. The ES size is designed against the engine performance and the proposed power sharing strategy by optimizing the flight altitude.
\end{abstract}

Keywords - hybrid propulsion; battery energy storage; fuel burn saving.

\section{INTRODUCTION}

There are vast efforts to move towards More Electric Aircraft (MEA) with motivation to reduce $\mathrm{CO}_{2}$ emission and to contribute in achieving a cleaner environment. There is also a huge movement from the aeronautic industry towards hybrid and fully electric propulsion, not only to reduce emissions but also to reduce audible noise and improve aircraft performance. NASA has stated goals for future hybrid/electric propulsion aircrafts in which the audible noise, $\mathrm{NO}_{\mathrm{x}}$ emissions, and fuel and energy consumption are reduced significantly, [1], e.g. the energy consumption is aimed to be reduced by $60 \%$ in 2025 . The adoption of hybrid and fully electric propulsion concept will give opportunities to decouple the operation of the engine from the propulsion system, and hence enables system components to operate at their maximum efficiency to reduce the overall fuel consumption of the engine, [2].

Cruise phase represents a significant portion of the flight mission and correspondingly, the largest opportunity for fuel burn reduction. Potential efficiency benefits that can be achieved by improving the cruise speed and altitude profiles are studied in [3]. The study has shown that speed and altitude are closely linked with aircraft performance and optimizing these profiles can offer significant fuel savings.

The efficiency of fuel burn varies with the level of the engine output power; the higher the output engine power, the less fuel consumption per $\mathrm{kW}$ of output power. This reveals an opportunity to reduce the fuel consumption by operating the engine at the maximum output power, and to store the excess in power produced into a battery energy storage for upcoming use.

High energy dense and efficient battery technologies are now commercially available, [4] and are being used in many applications from power systems to transportation, and for many reasons such as load levelling, power smoothing and power quality improvement, [5]-[7]. This concept can also be adopted for aircraft hybrid propulsion applications to save fuel via operating the engine at its highest efficiency, see Fig. 1. However, the installation of energy storage is like adding another source of power loss and more loading weight to the aircraft and therefore it looks like reducing the overall system efficiency rather than improving it. However, there is a possibility of reducing the overall system losses with the installation of energy storage, by adopting an intelligent energy management strategy to guarantee that the reduction in the engine fuel burn outweighs the energy loss by the energy storage system and hence improving the overall system efficiency.

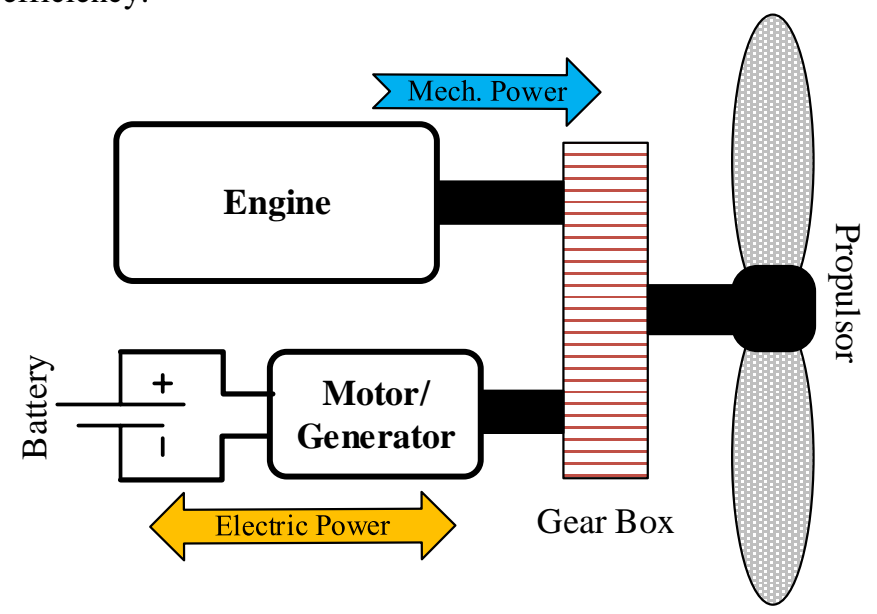

Fig. 1 Turboprop engine assisted by electric motor drive and energy storage system

In this paper, the battery energy storage system is designed to improve the engine fuel burn in cruise mode. A simple conceptual design approach is proposed to determine the optimal size of the battery ES and to maximise the range or endurance of the flight for the available fuel in the aircraft tank. The proposed power management strategy is discussed 
in section II and a numerical design example is presented in section III. Conclusions are drawn and given in section IV.

\section{The Design APPROACH OF A BATtery ENERGY StORAGE FOR FUEL SAVING IN CRUISING MODE}

In cruise mode, a simple power management cycle (for engine and battery energy storage) is proposed as shown in Fig. 2 .

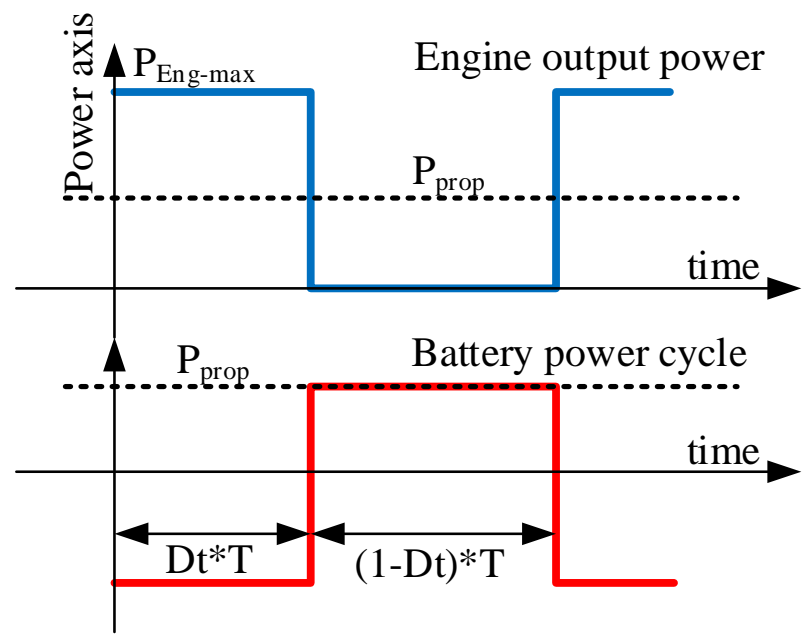

Fig. 2 Proposed power management cycle of the engine and the battery.

In this power management strategy, the Engine (Eng) is switched on and off alternatively in cycles with the battery energy storage (see Fig. 2). During switching on time, the engine is operated at its maximum output power to achieve efficient fuel burn and reduced Specific Fuel Consumption $(\mathrm{SFC}, \mathrm{kg} / \mathrm{s} / \mathrm{kW})$. The output power from the engine during switching on time is used to drive the propeller and to charge the battery. The stored energy in the battery is retrieved back in order to drive the propeller when the engine is switched off. Based on the proposed power management strategy, the design process is aiming to determine the optimal weight of the battery ES, the duty cycle ratio Dt of the switching on/off cycle of the engine and the aircraft cruising velocity at which the fuel saving in maximized for a given flight altitude. Simple/generic models for the aircraft drag, lift and SFC are used in the design algorithm, which we believe it provide sufficient details necessary to proof the concept of the design.

The models of the aircraft system variables and parameters such as air density, drag, lift and propulsion power as function of aircraft altitude and velocity are given in section II.A. Then, the approach on how to determine the battery size is detailed in section II.B. The generic model for engine fuel consumption and its relation to the flight parameters is given in section II.C. The possible amount of fuel saving is evaluated and discussed in section II.D.

\section{A. Basic Models of System Variables}

In general, the output power from the engine decreases with the decrease in air density at higher altitudes. The model of the air density variation against altitude is given in (1). The coefficients of the model in (1) are obtained by applying curve fitting to the data taken from the standard air-density versus altitude tables.

$$
\rho=\rho_{S L}+b_{1} A l t+b_{2} A l t^{2}
$$

Where: Alt is the aircraft altitude, m. $\rho$ is air density, $\mathrm{kg} / \mathrm{m}^{3}$. $\rho_{S L}$ is air density at sea level, $\mathrm{kg} / \mathrm{m}^{3} . b_{1}\left(\mathrm{~kg} / \mathrm{m}^{3} / \mathrm{m}\right)$ and $b_{2}$ $\left(\mathrm{kg} / \mathrm{m}^{3} / \mathrm{m}^{2}\right)$ are constants.

The aircraft drag (D) is function of the velocity (V), $\rho$ and the wing surface area $(\mathrm{S})$ and is given by:

$$
D=C_{D}\left(0.5 \rho V^{2}\right) S
$$

Where: $D$ is the aircraft drag, N.m. $C_{D}$ is the drag constant. $S$ is the wing surface area, $\mathrm{m}^{2} . V$ is the aircraft velocity, $\mathrm{m} / \mathrm{s}$.

The drag coefficient $\left(\mathrm{C}_{\mathrm{D}}\right)$ is also given by:

$$
C_{D}=C_{D 0}+k C_{L}^{2}
$$

Where: $C_{L}$ is the lift coefficient. $C_{D O}$ and $k$ are drag constants.

The lift coefficient is given by:

$$
C_{L}=\frac{W}{\left(0.5 \rho V^{2}\right) S}
$$

Where: $W$ is the total weight of the aircraft in $\mathrm{N}$.

By substituting (3), (4) into (2), the drag D as function of $W, V$ and $S$ is given by:

$$
D=\left[C_{D o}\left(0.5 \rho V^{2}\right) S+k \frac{W^{2}}{\left(0.5 \rho V^{2}\right) S}\right]
$$

The value of lift to drag ratio $(L / D)$ is a measure of aircraft's aerodynamic efficiency. The higher the lift force to drag means the aircraft can carry more weight with less propulsion power (i.e. less fuel consumption). The minimum drag occurs when parasite drag and induced drag are equal, [8], hence:

$$
C_{D_{o}}=k C_{L}^{2} \text { and, } C_{\text {Lmax }}=\sqrt{\frac{C_{D_{o}}}{k}}
$$

Where: $\mathrm{C}_{\mathrm{Lmax}}$ is the lift at the minimum drag.

Then from (4) and (5b), the aircraft velocity at minimum drag is given by:

$$
V=\sqrt{\frac{2 W}{\rho * S * C_{L \max }}}
$$

The velocity $\mathrm{V}$ of $(5 \mathrm{c})$ is the minimum velocity to keep the aircraft flying at a given altitude.

From (4), (5a), (5c) the propulsion power is given as function of aircraft velocity $\mathrm{V}$ and air-density $\rho$ : 


$$
\mathrm{P}_{\text {prop }}=\frac{\mathrm{DV}}{\eta_{\mathrm{P}}}=\frac{\mathrm{V}}{\eta_{\mathrm{P}}}\left[\mathrm{C}_{\mathrm{Do}}\left(0.5 \rho \mathrm{V}^{2}\right) \mathrm{S}+\mathrm{k} \frac{\mathrm{w}^{2}}{\left(0.5 \rho \mathrm{V}^{2}\right) \mathrm{S}}\right]
$$

Where: $\eta_{\mathrm{p}}$ is the propulsion efficiency, which can be obtained from the available charts for the propeller efficiency and/or thrust as a function of air density, aircraft velocity and engine speed in rpm.

The engine size is normally defined by its output power at the sea level and when the engine is operated at the permissible thermal (i.e. combustor temperature) and mechanical (i.e. turbine and compressor blades stress) limits. The maximum output power from the engine decreases with the increase in altitude and can be expressed in a simple/generic form as, [9]:

$$
\mathrm{P}_{\text {Eng-max }}=\mathrm{P}_{\text {Eng-SL }} \frac{\rho}{\rho_{\mathrm{SL}}}
$$

Where: $\mathrm{P}_{\text {Eng-SL }}$ is the engine output power at sea level.

\section{B. Sizing of Battery Energy Storage}

Based on the engine and the proposed battery power management cycle shown in Fig. 2, the relationship between the output power of the engine $\mathrm{P}_{\text {Eng-max }}$ (during switching on time of engine), the duty cycle $\mathrm{Dt}$ and $\mathrm{P}_{\text {prop }}$ can be derived from the energy balance during the power cycle as in (8a):

$$
\mathrm{TP}_{\text {Eng-max }} \mathrm{Dt}=\mathrm{TP}_{\text {prop }} \mathrm{Dt}+\mathrm{TP}_{\text {prop }}(1-\mathrm{Dt}) / \eta_{\mathrm{rt}}
$$
and hence from (8a), $\mathrm{P}_{\text {Eng-max }}$ is given as:

$$
\mathrm{P}_{\text {Eng-max }}=\left(\frac{1-\mathrm{Dt}}{\mathrm{Dt} \eta_{\mathrm{rt}}}+1\right) \mathrm{P}_{\text {prop }}
$$

Where: Dt is the duty cycle of engine switching on and off cycle, $\mathrm{T}$ is time period of the power cycle. $\eta_{\mathrm{rt}}$ is the round trip efficiency of the battery energy storage, (the ratio between the discharging and the charging energy of the battery). $\eta_{r t}$ is equal to the product of the charging and discharging efficiencies of the battery energy storage system.

The optimal operating value of Dt for a given altitude is determined from (8b) and (7). By knowing the value of Dt, the weight of the required battery energy storage will be determined based on the amount of energy to be stored during engine switch on time within the proposed power management cycle shown in Fig. 2. Hence, the weight of the battery is calculated as follows:

$$
\mathrm{W}_{\mathrm{bat}}=\frac{(1-\mathrm{Dt}) \mathrm{P}_{\text {prop }}}{\mathrm{Dt} * \eta_{\mathrm{rt}} * \mathrm{SP}_{\mathrm{bat}-\mathrm{ch}}}
$$

Where: $W_{\text {bat }}$ is the weight of the battery stack in $\mathrm{kg}$. $\mathrm{SP}_{\text {bat-ch }}$ $(\mathrm{W} / \mathrm{kg})$ is the specific charging power of the battery.

$\mathrm{SP}_{\text {bat-ch }}$ is chosen in this study to be equal to three times the battery Specific Energy density ( $\mathrm{SE}_{\mathrm{bat}}$ ), which means that the minimum time for charging the battery energy storage is $\sim 20$ minutes.
The weight of the power electronics and electrical machine is determined based on the maximum power to be handled by the battery during the charging and discharging cycle.

$$
\begin{array}{ll}
\mathrm{P}_{\mathrm{PE}}=\mathrm{P}_{\text {prop }} & \text { if }\left(\mathrm{P}_{\text {Eng-max }}-\mathrm{P}_{\text {prop }}\right)<\mathrm{P}_{\text {prop }} \\
\mathrm{P}_{\mathrm{PE}}=\left(\mathrm{P}_{\text {Eng-max }}-\mathrm{P}_{\text {prop }}\right) & \text { if }\left(\mathrm{P}_{\text {Eng-max }}-\mathrm{P}_{\text {prop }}\right) \geq \mathrm{P}_{\text {prop }}
\end{array}
$$

Where: $\mathrm{P}_{\mathrm{PE}}$ is the maximum electric power processed by the power electronics and the electrical machine.

The total weight of the power electronics and electrical machine $\mathrm{W}_{\mathrm{PE}}$ is given by:

$$
\mathrm{W}_{\mathrm{PE}}=\frac{\mathrm{P}_{\mathrm{PE}}}{\mathrm{PD}_{\mathrm{PE}}}
$$

Where: $\mathrm{PD}_{\mathrm{PE}}(\mathrm{W} / \mathrm{kg})$ is the power density of the power electronics and the electrical machine system.

The total weight of the energy storage $\left(\mathrm{W}_{\mathrm{ES}}\right)$ system is:

$$
\mathrm{W}_{\mathrm{ES}}=\mathrm{W}_{\mathrm{bat}}+\mathrm{W}_{\mathrm{PE}}
$$

\section{Fuel Consumption}

A generic and simple analytical model of the Specific Fuel Consumption (SFC) against engine output power is assumed as in (12). The model is designed to reflect the decrease in the SFC of the engine with the increase in the altitude and to represent the increase in the SFC with the decrease in the output power from the engine.

$$
\mathrm{SFC}=\mathrm{SFC}_{0}\left(1+\mathrm{c}_{1} \mathrm{e}^{-\mathrm{P}_{\text {Eng }} * \mathrm{C}_{2}}\right) \frac{\mathrm{V}_{\text {snd }}}{\mathrm{V}_{\text {snd-SL }}}
$$

Where: SFC is the Specific Fuel Consumption $(\mathrm{kg} / \mathrm{s} / \mathrm{kW})$ $\mathrm{SFC}_{0}$ is the theoretical minimum specific fuel consumption $(\mathrm{kg} / \mathrm{s} / \mathrm{kW}) . \mathrm{V}_{\text {snd }}$ is the sound speed at a given altitude, $\mathrm{m} / \mathrm{s}$. $\mathrm{V}_{\text {snd-SL }}$ is the sound speed at the sea level. $\mathrm{c}_{1}$ and $\mathrm{c}_{2}$ are generic constants.

The sound speed (in $\mathrm{m} / \mathrm{s}$ ) as function of the altitude is given by:

$$
\begin{array}{ll}
\mathrm{V}_{\text {snd }}=\mathrm{V}_{\text {snd-SL }}-\frac{\left(\mathrm{V}_{\text {snd-SL }}-295\right)}{11000} \text { Alt } & \text { Alt }<11000 \\
\mathrm{~V}_{\text {snd }}=295 & \text { Alt } \geq 11000
\end{array}
$$

The average rate of fuel consumption of the engine in case of using battery energy storage (as shown in Fig. 2) is:

$$
\mathrm{FC}_{\mathrm{ES}}=\mathrm{SFC}\left(\mathrm{P}_{\text {Eng-max }}\right) * \mathrm{P}_{\text {Eng-max }} * \mathrm{Dt}
$$

Where: $\mathrm{FC}_{\mathrm{ES}}$ is the average rate of fuel consumption in $\mathrm{kg} / \mathrm{s}$.

\section{Fuel Saving}

The rate of fuel consumption $\left(\mathrm{FC}_{\mathrm{No}-\mathrm{ES}}\right)$ of the engine in the case without using the battery energy storage is :

$$
\mathrm{FC}_{\text {No-ES }}=\operatorname{SFC}\left(\mathrm{P}_{\text {prop }}\right) * \mathrm{P}_{\text {prop }}
$$


From (13) and (14), the fuel saving per unit time is:

$$
\mathrm{FC}_{\text {saving }}=\mathrm{FC}_{\mathrm{No}-\mathrm{ES}}-\mathrm{FC}_{\mathrm{ES}}
$$

Where: $\mathrm{FC}_{\text {saving }}$ is rate of fuel saving in $\mathrm{kg} / \mathrm{s}$.

The fuel saving per unit distance $(\mathrm{kg} / \mathrm{km})$ is then given by:

$$
\mathrm{FC}_{\text {saving }}=1000 *\left(\frac{\mathrm{FC}_{\mathrm{No}-\mathrm{ES}}}{\mathrm{V}_{\mathrm{No}-\mathrm{ES}}}-\frac{\mathrm{FC}_{\mathrm{ES}}}{\mathrm{V}_{\mathrm{ES}}}\right)
$$

The model equations from (1) to (16) give a simple/generic and sufficiently accurate modelling approach that can be used to evaluate the tendency of fuel saving when using battery energy storage system with the engine and operating the proposed hybrid propulsion system (Fig. 1) according to the proposed power management cycle shown in Fig. 2.

\section{NUMERICAL DESIGN EXAMPLE}

The equations (from (1) to (16)) are used in the design algorithm to determine the size of the battery energy storage and to investigate the amount of fuel saving during cruise mode. The aircraft and system parameters used in this study are listed in Table 1.

Table 1. System parameters and coefficients used in the design algorithm.

\begin{tabular}{|l|l|}
\hline $\mathrm{W}_{\mathrm{AC}}$ & aircraft weight, $2500 \mathrm{~kg}$ \\
\hline $\mathrm{S}$ & aircraft wing surface area, $16.7225 \mathrm{~m} 2$ \\
\hline $\mathrm{C}_{\mathrm{D} 0}$ & drag constants $(5 \mathrm{~b}), 0.018$. \\
\hline $\mathrm{k}$ & drag constants $(5 \mathrm{~b}), 0.0950$. \\
\hline$\rho_{S L}$ & air density at sea level, $1.2041 \mathrm{~kg} / \mathrm{m} 3$. \\
\hline $\mathrm{b}_{1}$ & constant $(1),-0.00010323$. \\
\hline $\mathrm{b}_{2}$ & constant $(1), 2.4181 \mathrm{e}-9$. \\
\hline$\eta \mathrm{p}$ & the propulsion efficiency, 0.91. \\
\hline$P_{E n g-S L}$ & the engine output power at sea level, $1000 \mathrm{~kW}$. \\
\hline$\eta_{r t}$ & $\begin{array}{l}\text { the round trip efficiency of the battery energy } \\
\text { storage, } 0.9 .\end{array}$ \\
\hline $\mathrm{SP}_{\mathrm{bat}-\mathrm{ch}}$ & specific charging power of battery, $0.6 \mathrm{~kW} / \mathrm{kg}$. \\
\hline $\mathrm{SE}_{\mathrm{bat}}$ & specific energy density of battery, $0.2 \mathrm{kWhr} / \mathrm{kg}$. \\
\hline $\mathrm{PD}_{\mathrm{PE}}$ & $\begin{array}{l}\text { the power density of the power electronics and the } \\
\text { electrical machine, } 2 \mathrm{~kW} / \mathrm{kg} .\end{array}$ \\
\hline $\mathrm{SFC}_{0}$ & $\begin{array}{l}\text { the minimum specific fuel consumption, } 4.63 \mathrm{e}-05 \\
\text { (kg/s) } / \mathrm{kW} .\end{array}$ \\
\hline $\mathrm{V}_{\mathrm{snd}-\mathrm{SL}}$ & the sound speed at sea level, $340.3 \mathrm{~m} / \mathrm{s}$. \\
\hline $\mathrm{c}_{1}$ & Generic constant $(12),=3$. \\
\hline $\mathrm{c}_{2}$ & Generic constant $(12),=0.0061$. \\
\hline
\end{tabular}

\section{A. Engine Fuel Consumption}

The aircraft parameters and constants in Table 1 are used to calculate the SFC versus the engine output power at different altitudes using (12). Fig. 3 shows the variation of the SFC with the altitude and the engine output power.
The maximum output power $\mathrm{P}_{\text {Eng-max }}$ from the engine at different altitudes is determined using (7) and is mapped on the SFC lines in red square markers as shown in Fig. 3. The red square markers of the $\mathrm{P}_{\text {Eng-max }}$ form the trajectory that gives the variation of the SFC of the engine against its maximum output power at different altitudes. The $\mathrm{P}_{\text {Eng-max }}$ at sea level $(0 \mathrm{~km})$ is considered equal to $1 \mathrm{MW}$ and it decreases with the increase in altitude.

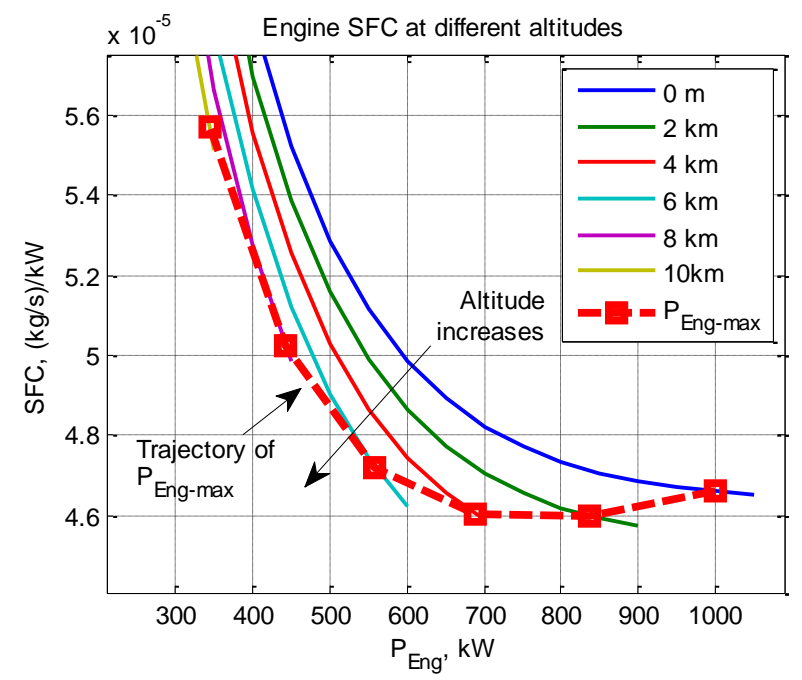

Fig. $3 \mathrm{SFC}(\mathrm{kg} / \mathrm{s} / \mathrm{kW})$ versus engine output power at different altitudes

The engine maximum output power, the propulsion power and the optimal aircraft velocity (i.e. when $\mathrm{L} / \mathrm{D}$ ratio is maximum) are calculated using the system parameters listed in Table 1 for an altitude range from 0 to $11 \mathrm{~km}$ and the results are shown in Fig. 4. The power difference between the engine output power $\mathrm{P}_{\text {Eng-max }}$ and the propulsion power $\mathrm{P}_{\text {prop }}$ at any altitude is the power available for charging the battery. The available charging power at different altitudes is highlighted by green double arrow lines as shown in Fig. 4. The Aircraft ceiling altitude at which the engine maximum output power is just equal to the propulsion power is marked by a red circle.

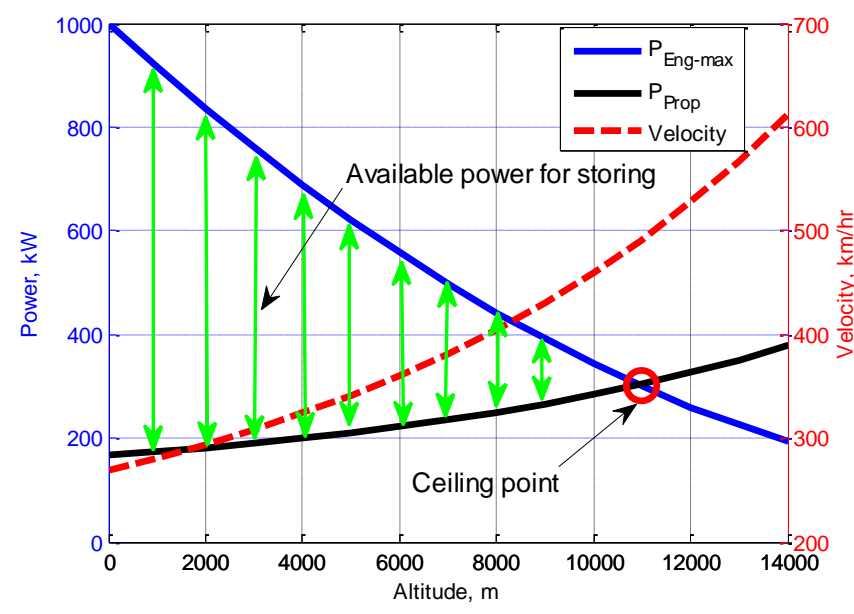

Fig. 4 Cruising velocity for maximum L/D at different altitudes. 


\section{B. Energy Storage Sizing and Fuel Saving}

In order to determine the amount of fuel saving when using the battery energy storage, first the rate of fuel consumption of the engine without using energy storage should be calculated at the optimal aircraft velocity and then compared with the case of using battery energy storage. The weight of the energy storage system will be determined using an iterative algorithm with assumption that the engine is operated at $\mathrm{P}_{\text {Eng-max }}$ during the switch on time and the aircraft is cruising at the optimal velocity, (5c). The weight of the battery Energy Storage (ES) is calculated based on the available power for charging the battery, (see Fig. 4) and the specific power density of the battery and the power electronics used. The weight of the ES is added to the weight of the aircraft and the calculation of the required propulsion power and the aircraft velocity is iterated until finding out the final weight of the ES and the optimal aircraft velocity. The results obtained for both cases (with and without ES) are shown in Fig. 5. The charging power of the battery ES is also shown in Fig. 5.

It is noted that the cruising velocity in case of using ES is higher than the case without ES. The added weight of the ES increases the overall weight of the aircraft and hence the optimal cursing velocity should be higher to compensate for the increased lift needed, and this results in increase in the required propulsion power.

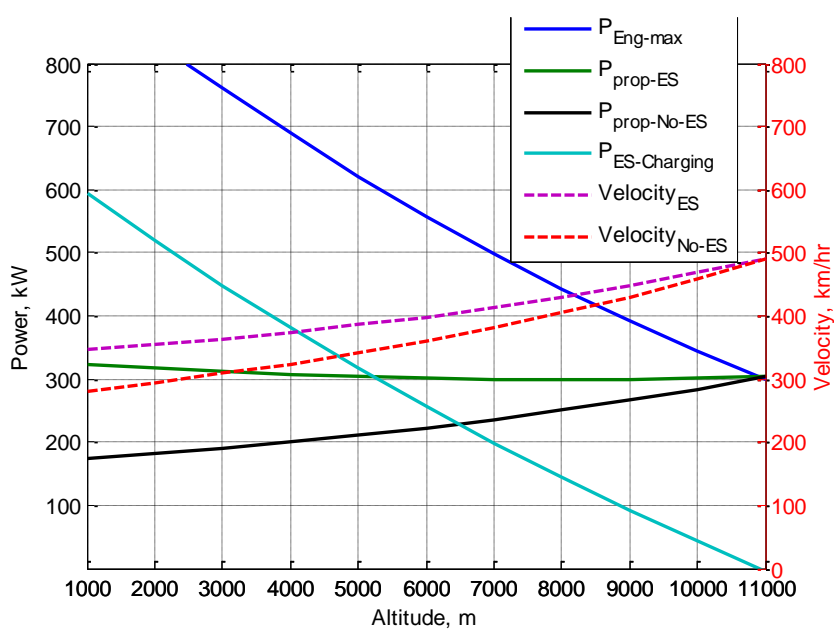

Fig. 5 Cruising velocity at different altitudes with and without ES.

The fuel consumption per unit distance (range) for the two cases, with and without ES are calculated (16) and plotted in Fig. 6a. The \% of fuel saving per unit distance $(\mathrm{kg} / \mathrm{km})$ due to using ES is calculated and plotted in Fig. 6b. It is noted that the maximum $\%$ of fuel saving per unit distance occurs at $\sim 4000 \mathrm{~m}$ altitude. This means that, the use of the ES will increase the flight range for a given amount of fuel in the aircraft tank and the maximum achievable range occurs when the aircraft is cruising at $\sim 4000 \mathrm{~m}$ altitude.

The fuel consumption per unit time (endurance) for the cases with and without using ES are calculated and plotted in
Fig. 7a. The $\%$ of fuel saving per unit time $(\mathrm{kg} / \mathrm{s})$ due to using ES is plotted in Fig. 7b. The maximum fuel saving per unit time occurs at altitude of $\sim 5500 \mathrm{~m}$. This means that the aircraft endurance can be increased using ES and the maximum achievable endurance occurs when the aircraft is cruising at $5500 \mathrm{~m}$ altitude.

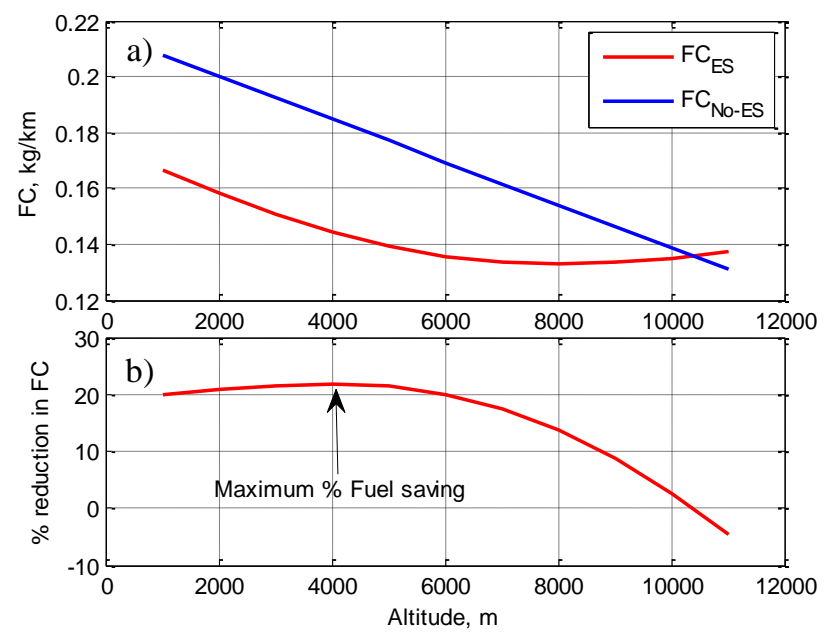

Fig. 6 Fuel saving per unit distance in case of using ES

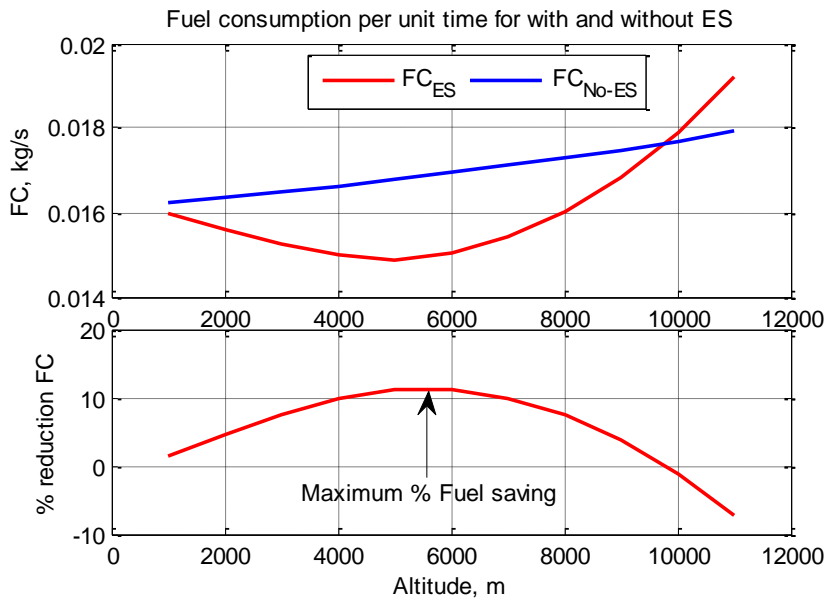

Fig. 7 Fuel saving per unit time in case of using ES

The calculated weight of the ES and the duty cycle Dt of switching on and off the engine at different altitudes (without taking into account the aircraft on-board load power $\mathrm{P}_{\mathrm{L}}$ ) are given in Fig. 8. It is noted that the amount of fuel saving per unit distance (range) is maximum when the aircraft flies at low altitudes $(\sim 4 \mathrm{~km})$ and the corresponding duty cycle is less than 0.5 , it is $\sim 0.47$ and hence the engine will be switched off for a longer time than the switching on time. It is also noted, although the weight of ES is high and it is equal to $\sim 800 \mathrm{~kg}$ (note that the aircraft weight is $2500 \mathrm{~kg}$ ), it is still possible to reduce fuel consumption. On the other hand, the maximum fuel saving per unit time (endurance) occurs at higher altitude $\sim 5.5 \mathrm{~km}$ and the duty cycle is higher $\sim 0.55$ and the weight of the ES is less - around $\sim 620 \mathrm{~kg}$. 


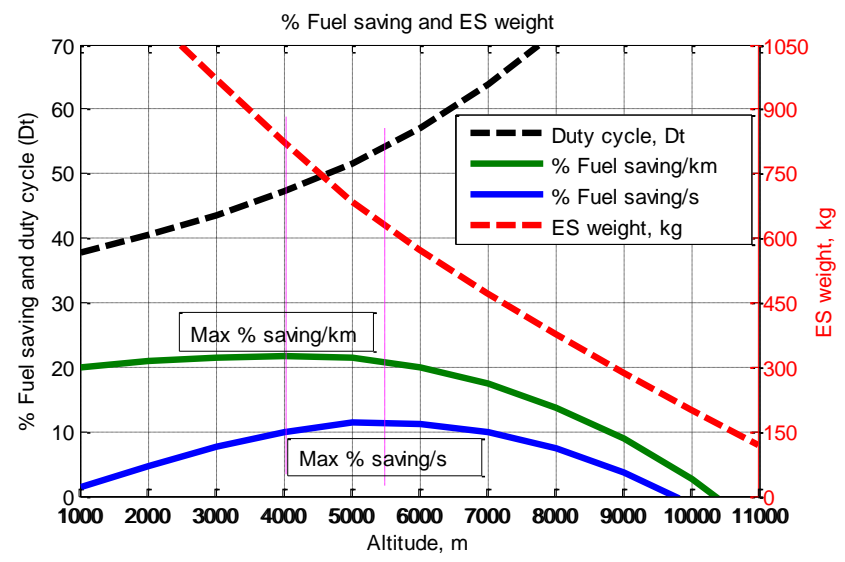

Fig. 8 The weight and operating duty cycle of the ES versus altitude, $\left(\mathrm{P}_{\mathrm{L}}=\right.$ $0 \mathrm{~kW})$.

The design of the battery ES and the calculations of the fuel saving are repeated with considering the aircraft on-board load power to be supplied by the engine when it is switched on or by the battery when the engine is switched off. The on-board load power $\mathrm{P}_{\mathrm{L}}$ is assumed constant and equal to $35 \mathrm{~kW}$. Similar design results to that shown in Fig. 8 are shown in Fig. 9 for the case considering $\mathrm{P}_{\mathrm{L}}=35 \mathrm{~kW}$. It is noted that the operating points for maximum fuel saving are moved to lower attitudes and the \% of fuel saving is less in comparison to the results obtained for the case of $\mathrm{P}_{\mathrm{L}}=0 \mathrm{~kW}$ (shown in Fig. 8).

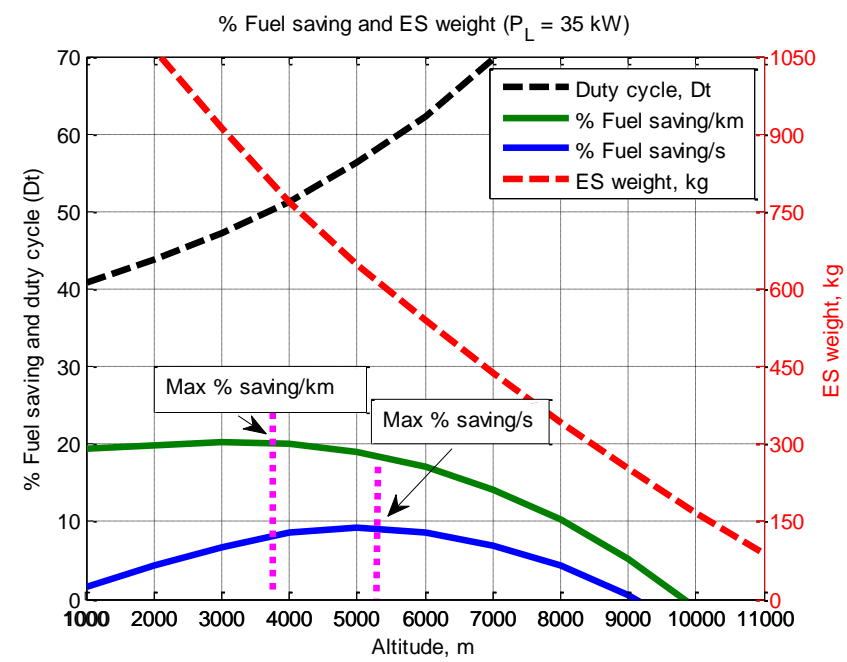

Fig. 9 The weight and operating duty cycle of the ES versus altitude, $\left(\mathrm{P}_{\mathrm{L}}=35\right.$ $\mathrm{kW})$

\section{CONCLUSIONS}

The paper has presented a conceptual design approach of battery energy storage for an aircraft hybrid propulsion system. The design is based on simple and generic models of the aircraft aerodynamics and specific fuel consumption but believed to be sufficient to identify tendencies of possible situations to reduce fuel consumption. A simple power management cycle is proposed where the engine is to be switched on and operated at its maximum output power in order to provide the required power for propulsion as well as charging the battery until it is fully charged and then the engine is switched off and the battery ES starts to provide the aircraft propulsion power. The battery ES design optimization criteria is set to be either to achieve longer endurance or extended flight range. The results of the design for maximum flight range has shown that a maximum $\%$ of fuel saving of $\sim 22 \%$ can be achieved when the aircraft optimal flying altitude is $\sim 4$ $\mathrm{km}$. On the other hand, the design for maximum endurance has shown less $\%$ of fuel saving $\sim 11 \%$, but at higher altitude of $\sim 5.5 \mathrm{~km}$. In general, the design study has clearly shown the possibility to significantly reduce fuel consumption by adopting the proposed hybrid propulsion concept presented in this paper. This would encourage using detailed and practical models of the system components in future research work in order to improve the accuracy of the proposed design approach.

\section{REFERENCES}

[1] B. Sarlioglu and C. T. Morris, "More Electric Aircraft: Review, Challenges, and Opportunities for Commercial Transport Aircraft", IEEE transactions on Transportation Electrification, Vol. 1, No. 1, June 2015, pp. 54-64.

[2] J. L. Felder, G. V. Brown, H. D. Kim, and J. Chu, "Turboelectric distributed propulsion in a hybrid wing body aircraft," in Proc. Int Symp. Air Breath Engines Conf., 2011, pp. 1-20.

[3] J. A. Lovegren and R. J. Hansman, "Estimation of Potential Aircraft Fuel Burn Reduction in Cruise vis Speed and Altitude Optimization Strategies", Report No. ICAT-2011-03, MIT International Centre for Air Transportation (ICAT), Department of Aeronautics \& Astronautics Massachusetts Institute of Technology Cambridge, MA 02139 USA, February 2011.

[4] S. Alahakoon and M. Leksell, "Emerging Energy Storage Solutions for Transportation - A Review: An Insight into Road, Rail, Sea and Air Transportation Applications", International Conference on Electrical Systems for Aircraft, Railway, Ship Propulsion and Road Vehicles (ESARS), 3-5 March 2015.

[5] M. F. Romlie, M. Rashed, C. Klumpner and G. M. Asher, "An Analysis of Efficiency Improvement with the Installation of Energy Storage in Power Systems", The 7th IET International Conference on Power Electronics, Machines and Drives, PEMD, 8-10 April 2014, Midland Hotel, Manchester, UK.

[6] W. Jewell and $\mathrm{Z}$. Hu, "The role of energy storage in transmission and distribution efficiency," in Transmission and Distribution Conference and Exposition (T\&D), 2012 IEEE PES, 2012, pp. 14.

[7] B. P. Roberts and C. Sandberg, "The Role of Energy Storage in Development of Smart Grids," IEEE Proc., vol. 99, no. 6, pp. 1139-1144, 2011.

[8] Egbert Torenbeek, "Advanced Aircraft Design: Conceptual Design, Analysis and Optimization of Subsonic Civil Airplanes", John Wiley and Sons, Ltd., ISBN: 9781119969303, 2013.

[9] Steven A. Brandt and Randall J. Stiles, "Introduction to Aeronautics: A Design Perspective (AIAA Education Series)", Amer Inst of Aeronautics \& (July 1997). 